\title{
Neglected disease boost
}

\section{Fresh funding aims to raise awareness and improve control measures.}

The Bill \& Melinda Gates Foundation has called for a worldwide push to slash the burden of neglected tropical diseases such as elephantiasis, trachoma and schistosomiasis by 2020.

On 30 January, Bill Gates announced a US\$34-million grant to leverage new funding globally to prevent and treat these illnesses, which affect 1.4 billion people. The money will go to an international alliance, the Global Network for Neglected Tropical Diseases, which aims to raise awareness and bring previously fragmented disease-specific efforts under a common umbrella to better coordinate fundraising and field operations.

The trick, says Gates, is bringing in the substantial new investment needed to drastically scale up control measures using existing tools.

Such scale-up has already proved its mettle: take, for example, lymphatic filariasis, a devastating parasitic disease usually known by its worst manifestation, elephantiasis. Just nine years ago, drugs for lymphatic filariasis reached only 25 million people in 12 countries; more than one billion people in 83 countries are at risk. But a public-private partnership, the Global Programme to Eliminate Lymphatic Filariasis, whose secretariat is at the Liverpool School of Tropical Medicine, UK, is now bringing vital drugs to 570 million people in 48 countries annually. The programme, launched in 2000 and jump-started with a \$20-million grant from Gates, estimates that it has prevented the disease in 6.6 million newborns and prevented 2.2 million new serious clinical cases, as well as stopping 9.5 million people already infected from developing severe complications ${ }^{1}$.

"The alliance has amply demonstrated proof-of-principle that rapid country scaleup makes a difference," says Alan Fenwick, a parasitologist at Imperial College London and head of the board of the Schistosomiasis Control Initiative.

The Global Network, inaugurated by former President Bill Clinton in 2006, is headquartered at the Sabin Vaccine Institute in Washington DC. With the new Gates money it hopes to drastically step up prevention and treatment of the seven most common neglected diseases that can be prevented and treated with existing drugs for about 50 cents per person annually - trachoma, onchocerciasis, schistosomiasis, lymphatic filariasis, trichuriasis, hookworm and ascariasis.

The key is negotiating donations of billions of tablets from drug companies and purchasing others at cheap rates by negotiating bulk deals at a global scale, at prices far below those that would be attainable by any single country. A 'rapid impact package' - a cocktail of four

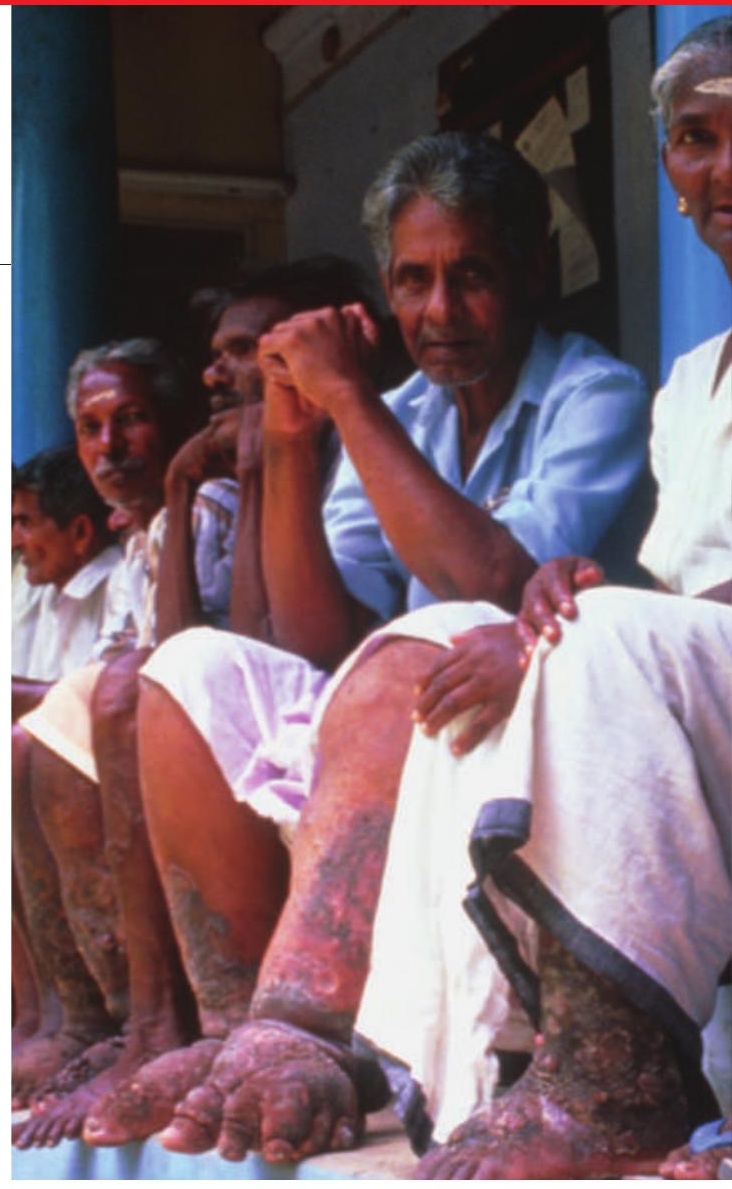

drugs that targets all seven diseases in a single treatment - is then used for mass preventative chemotherapy across entire populations.

The huge logistics are handled by an innovative community-based approach, made up of far-reaching networks of hundreds of thousands of volunteers in individual communities, and local health services. "You can put thousands of drugs on the back of a bicycle," says David Molyneux, a parasitologist at the Liverpool School of Tropical Medicine and

\section{Dutch university slashes evolution staff}

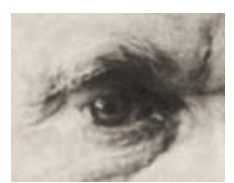

Darwin 200
The Year of Darwin has got off to a bad start in the Netherlands, where a national reorganization of university budgets has led Leiden University to sack its classical

evolutionary-biology staff.

"There will be no one left who can teach natural selection," says population ecologist Jacques van Alphen, one of half a dozen tenured professors who will lose their jobs on 1 March. Some technicians and postdocs will also be fired.

The scientists are challenging the legality of the dismissals in court, and have launched a petition that has been signed by more than 3,000 researchers worldwide.
They claim that their jobs have been eliminated in favour of jobs in molecular biology. Around 30 faculty members will remain on the staff at the university's Institute of Biology.

Like all universities in the Netherlands, Leiden is experiencing the consequences of a decision by science minister Ronald Plasterk, a former molecular geneticist, to introduce greater competition in the scientific community.

Last September, the government decided to transfer $€ 100$ million (US $\$ 130$ million) of its budget for universities to the NWO, the Dutch granting agency, for distribution through national competition. The sudden shortfall has meant that universities with little financial buffering, such as Leiden, are having to cut into their own flesh. Leiden found itself with a shortfall of $€ 10$ million $-€ 2.5$ million of which it passed on to the Institute of Biology.

Mathematician Sjoerd Verduyn Lunel, dean of natural sciences, \section{says the institute considered carefully where it would trim. "We applied the same criteria for identifying where to make the cuts as the government \\ "There will be no one left who can teach natural selection."} uses to fund the universities," he says. The list of criteria includes factors such as the numbers of students and income from competitive grants.

The molecular biosciences have been 
